\title{
PROJETO INTEGRADOR COMO ELEMENTO DE INOVAÇÃO EM CURSOS A DISTÂNCIA: UM ESTUDO DE CASO
}

\author{
LONDRINA/PR MAIO/2018
}

\author{
Leandro Henrique Magalhães - UniFil - Imagalhaes1974@gmail.com \\ Camila Fernandes de Lima - UniFil - camila.lima@unifil.br \\ Paula Ferreira - UniFil - paula.ferreira@unifil.br
}

Tipo: Relato de Experiência Inovadora (EI)

Categoria: Métodos e Tecnologias

Setor Educacional: EDUCAÇÃO SUPERIOR

\begin{abstract}
RESUMO
O presente trabalho pretende apresentar uma experiência de atividade integradora desenvolvida nos cursos de graduação de um Centro Universitário localizado no Estado do Paraná. A referida instituição atua na Educação a Distância desde o ano de 2008, e está credenciada para oferta de cursos superiores a distância desde o ano de 2015. Em busca de levar estratégias interdisciplinares e elementos de metodologias ativas para seus cursos totalmente a distância, desenvolveu a concepção de um projeto integrador, trabalho a ser desenvolvido pelos alunos, que a partir de uma temática específica, integra as disciplinas do bloco em que os alunos estão matriculados, em um processo que se intensifica à medida que o curso avança.
\end{abstract}

Palavras-chave: Educação a Distância, Interdisciplinaridade, Projeto Integrador, Metodologias Ativas

\section{AGRADECIMENTOS}

AO DR. ELEAZAR FERREIRA, REITOR DA UNIFIL. E A PAULA FERREIRA, GERENTE DE EAD DA UNIFIL. 
Introdução

A Educação a Distância tem demonstrado crescimento relevante no nosso País quando comparado ao Ensino Superior na modalidade presencial. Diferentes propostas, diversas linguagens e amplos recursos tecnológicos, bem como educacionais têm sido aplicáveis nesta modalidade. Com isso, tais elementos têm a característica de gerir um sistema integrado, capaz de favorecer os recursos humanas e aspectos pedagógicos. De forma desafiadora, o pedagógico ganha uma maior complexidade no processo da EAD, em especial, quando se tem a proposta para uma metodologia ativa.

Sendo assim, propõe-se como objetivo apresentar uma experiência de atividade integradora, desenvolvida por um Centro Universitário localizado no Estado do Paraná, visando propiciar experiências de aprendizagem que se sustentem por um diálogo entre o aprendido e a realidade do trabalho. Esta atividade, além de proporcionar a integração entre conhecimentos e disciplinas, possibilita o uso de elementos de metodologias ativas, dinamizando e garantindo maior autonomia no processo de aprendizados dos alunos envolvidos.

A experiência metodológica vivenciada com a atividade integradora, mostrou-se desafiadora e significativa e, por isso, motivou a realização do relato. Assim, esse estudo se propõe a apresentar a vivência da utilização do projeto integrador, que configura-se em uma atividade interdisciplinar partindo de uma temática específica, da qual integra as disciplinas do bloco de um semestre em que os alunos estão matriculados, em um processo que se intensifica à medida que o curso avança.

A presente pesquisa classifica-se pela Abordagem Qualitativa, uma vez que a participação na realidade investigada, por meio do processo e ainda "[...] busca a interpretação no lugar da mensuração, a descoberta em lugar da constatação, valoriza a indução e assume que fatos e valores estão intimamente relacionados [...]" (ANDRÉ, 2004, p. 17), admitindo, assim, uma compreensão mais ampla e clara em relação ao objeto de estudo. A pesquisa sendo descritiva, configura-se em relato de experiência com aporte teórico, com enfoque em estudo de caso.

Os resultados da pesquisa apontam para a importância da continuidade da proposta metodológica, por meio do uso do Projeto Integrador, por permitir a associação dos conhecimentos teóricos práticos. 


\section{Objetivos}

O presente trabalho tem por objetivo apresentar uma experiência de atividade integradora, desenvolvida por um Centro Universitário localizado no Estado do Paraná. Esta atividade, além de proporcionar a integração entre conhecimentos e disciplinas, possibilita o uso de elementos de metodologias ativas, dinamizando e garantindo maior autonomia no processo de aprendizados dos alunos envolvidos.

\section{Referenciais Teóricos}

O Centro Universitário em questão parte do princípio de que o aluno, e assim a aprendizagem, deve ter o protagonismo principal. Desde a promulgação da LDB Lei no 9.394, de 20 de dezembro de 1996, houve um aumento significativo das vagas ofertadas no Ensino Superior. $O$ último Censo da Educação Superior, divulgado pelo Instituto Nacional de Estudos e Pesquisa Educacionais Anísio Teixeira - INEP, foram oferecidas mais de 10,6 milhões de vagas em cursos de graduação, sendo $73,8 \%$ vagas novas e $26,0 \%$, vagas remanescentes.

O número de oferta de vagas teve como consequência a chegada de acadêmicos muito heterogêneos no que diz respeito à formação e também ao tempo disponível para os estudos.

Com isso, as instituições particulares passaram a receber um contingente carente em relação à formação básica para o desenvolvimento de estudos em nível de graduação. Desta forma, a metodologia a ser adotada deve contemplar o resgate e o preparo destes alunos para que consigam atingir o nível desejado proposto de formação. Para tanto, as atividades realizadas priorizam uma metodologia participativa, considerando os alunos como principal personagem do processo de aprendizagem e buscando despertar o desejo pelos conteúdos da área de formação escolhida (MORAN, 2015).

Para que esta abordagem metodológica se concretize é de suma importância que - corpo docente e discente compreenda qual é a proposta em termos de competências e habilidades que se pretende desenvolver e permitir a percepção natural dos princípios da interdisciplinaridade (foco principal) e que certamente devem desencadear a necessidade de busca por conhecimentos de outras áreas. Daí a importância do Projeto Integrador, como veremos.

Assim, a metodologia adotada se pauta em ações interdisciplinares que 
incentivam o aprender a aprender, uma vez que a informação está disponível em várias categorias e fontes, podendo ser acessadas por qualquer pessoa interessada; além da quantidade de conhecimentos produzidos estarem aumentando numa velocidade cada vez maior (MORIN, 2002).

Sobre essa concepção de aprendizagem, busca-se uma metodologia que valoriza o desenvolvimento do aluno, estimula sua capacidade de buscar informações, centrada na resolução de problemas, respeitando as características individuais, 0 ritmo e o estilo próprio de cada um. Assim sendo, nesta perspectiva, corrobora com os princípios teóricos de Jacques Delors (1998), presidente da Comissão sobre a Educação no Século XXI, criada pela Unesco: a educação, que é a chave do futuro, descansa sobre quatro pilares: aprender a conhecer, aprender a fazer, aprender a ser e aprender a viver junto. Nesta mesma perspectiva, Edgar Morin (2002) acrescentou a estes pilares a necessidade de "aprender a aprender $\mathrm{e}$ reaprender a pensar", buscando uma educação que cure a cegueira do conhecimento; que garanta o conhecimento pertinente; que ensine a condição humana; a compreensão; a identidade; enfrentar as incertezas; e praticar a ética do gênero humano.

Assim, o encaminhamento metodológico pauta-se por ações facilitadoras, num processo de mediação com a própria aprendizagem do sujeito e não, simplesmente no repasse de informações. Está centrada no desenvolvimento intelectual do aluno, por meio da articulação teoria e prática, visado habilidades e competências compatíveis com o perfil vislumbrado para os egressos.

Diante desta perspectiva, o Centro Universitário em questão tem o objetivo de desenvolver em seus alunos responsabilidade e autonomia para intervir na realidade, o que pressupõe um comprometimento institucional com a formação de um aluno com conhecimentos, habilidades e valores para agir criticamente no contexto social, político e econômico.

Encontra-se assim respaldada na concepção do construtivismo de Piaget (1971), o qual coloca ênfase na construção do conhecimento pela ação do sujeito sobre o objeto do conhecimento. Nesta concepção, os professores devem assumir a responsabilidade de promover o desenvolvimento cognitivo de seus mediados, entendendo que a aprendizagem, acontece por meio de uma interação mediada de qualidade, que conduz ao desenvolvimento dos sujeitos, permitindo atingir níveis cada vez mais altos de autonomia, objetivo maior de qualquer aprendizagem humana. 
A articulação entre a teoria e a prática podem e devem ser consideradas nas especificidades que as diferenciam, no entanto, ainda que distintas, são inseparáveis, e o Projeto Integrador, como proposto, permite diminuir a distância entre aquilo que se sabe e aquilo que se compreende, integrando os conhecimento e atitudes construídas a partir de prática dialógica. Tal interação social, baseia-se na perspectiva teórica do sociointeracionismo de Vigotsky (1998), compreendendo-se os alunos como seres ativos, que constroem conhecimentos no seu contexto geográfico, cultural, social, político e histórico.

Diante disso, o Projeto Integrador, como atividade fim de cada bloco de estudos, se propõe a criar, desenvolver e implementar em seus alunos estudos/atividades cognitivamente motivadoras, por meio de um método de trabalho que garante a mediação, a interatividade e a construção.

O modelo pedagógico adotado, que tem como ponto alto o Projeto Integrador, parte de uma percepção que alia a necessidade de um trabalho interdisciplinar, sendo compreendido, como a relação dos conteúdos estabelecidos entre duas ou mais disciplinas afim de aprofundar o conhecimento e levar dinâmica ao ensino e ainda, configura-se como uma atividade essencial na busca da articulação das competências, capazes de contribuir para evidenciar as aprendizagens formativas do estudante, aliados com a prática profissional, com o uso de metodologias ativas, que baseiam-se, de acordo com Berbel (2011), formas de desenvolver o processo de aprender, utilizando experiências reais ou simuladas, visando às condições de solucionar, com sucesso, desafios advindos das atividades essenciais da prática social, em diferentes contextos

\section{Procedimentos Metodológicos}

O Procedimento Metodológico aqui apresentado classifica-se pela Abordagem Qualitativa, sendo uma pesquisa descritiva, configura-se em relato de experiência com aporte teórico, com enfoque em estudo de caso. Apresenta-se a metodologia da atividade integradora disciplina, os procedimentos didáticopedagógicos, os quais norteiam o planejamento e execução do projeto integrador a partir das temáticas utilizadas.

Os dados foram observados a partir dos documentos relacionados ao Projeto Integrador, de uma análise preliminar sobre o plano das atividades propostas, roteiros de aprendizagem, produções dos acadêmicos e, demais atividades disponibilizadas no AVA. Os procedimentos adotados, permitiu obter uma melhor 
confiabilidade sobre a coleta de dados realizadas, decorrentes da preocupação em assegurar a validade e confiabilidade dos achados e das análises.

Apresentação e Discussão dos Resultados

Como apresentado, a política de ensino adotada pelo Centro Universitário em questão está fundamentada nos princípios da autonomia, da criação e do compartilhamento do conhecimento. Os docentes articulam os conteúdos com as questões vivenciadas pelos alunos em sua vida profissional e social, relacionando os temas trabalhados com as outras disciplinas, permitindo ao aluno compreender a interdisciplinaridade e a transdisciplinaridade. Assim, a interdisciplinaridade efetivamente torna-se um meio de se trabalhar com conhecimento no qual se busca a reintegração de procedimentos acadêmicos, que ficaram isolados uns dos outros pelo método disciplinar.

Entende-se ser necessário uma visão adequada e abrangente da realidade, que muitas vezes se apresenta de maneira fragmentada. A partir destes preceitos foi constituído o Projeto Integrador, implantando em todos os cursos de graduação a partir do ano de 2017, o qual consiste na integração das várias disciplinas disponibilizadas no curso visando também sua aplicabilidade para a vida profissional do egresso. A proposta do projeto visa promover de forma efetiva e ativa, a integração entre a teoria e a prática, permitindo assim, aos acadêmicos refletir sobre o temáticas importantes e de destaque na àrea de formação do curso.

No que se refere a sua aplicabilidade, o Projeto Integrador está organizado em cinco etapas:

Etapa 1: Reunião didático-pedagógica com os docentes envolvidos nas disciplinas do bloco vigente, bem como o coordenador do curso, a fim de levantar temas importantes e que estão relacionados aos conteúdos e saberes trabalhados nas disciplinas do módulo. Assim, é realizado a definição do tema gerador para o projeto integrador e os passos dos quais os estudantes deverão percorrer para execução.. Ressalta-se que para a elaboração do projeto integrador, devem ser sistematizadas as fases de forma que tal atividade seja significativa e, ainda possa, permitir um espaço para articulação das competências desenvolvidas.

Etapa 2: Disponibilização de entrevistas e debates com os professores das disciplinas envolvidas, além de convidados. Neste recurso o tema a ser discutido, 
que envolva os conteúdos trabalhados pelos alunos naquele módulo é apresentado. Conforme o curso avança, as atividades tornam-se mais complexas, incorporando temáticas que levem os alunos a mobilizarem os conhecimentos, competências e habilidades trabalhados nos módulos anteriores. São disponibilizados também material complementar, como artigos acadêmicos. Com isso, espera-se que os envolvidos alcancem uma visão integral, interdisciplinar e prática.

Etapa 3: Após a apropriação do material disponibilizados aos alunos, é levantada uma problematização, oportunizando ao discente uma reflexão teórica com vistas a encontrar uma solução prática para o problema proposto. Isso vem de acordo com Moran (2015, p. 19), afirmando que "nas metodologias ativas de aprendizagem, o aprendizado se dá a partir de problemas e situações reais; os mesmos que os alunos vivenciarão depois na vida profissional, de forma antecipada, durante o curso".

Etapa 4: Direcionamento de pesquisa e análise crítica em grupos e/ou individual, abrangendo os tópicos levantados pelo corpo docente do curso. As atividades quando são em grupos, permitem aos alunos debaterem entre eles, utilizando as ferramentas de comunicação como - fóruns para momentos assíncronos e conferências, para momentos síncronos. Os acadêmicos, também, contam com o auxílio dos tutores a fim de tirar dúvidas e debater assuntos relevantes à temática proposta. Os trabalhos produzidos são protocolados via Ambiente Virtual de Aprendizado. A avaliação do processo de ensino e aprendizagem deste projeto ocorre forma formativa processual. Por meio da execução do trabalho do desenvolvimento.

Etapa 5: Discussão para análise com os docentes das disciplinas envolvidas, coordenação e tutores do curso, a respeito das percepções vivenciadas com a execução do projeto integrador, trazendo em destaque as produções dos acadêmicos.

Os resultados vindouros das discussões revelam um bom nível de participação, interesse e desempenho dos estudantes com o projeto integrador, este se mostra como alternativa metodológica positiva por associar os conhecimentos, bem como as competências práticas envolvidas nos saberes das disciplinas da qual os acadêmicos precisam demonstrar, além disso, é possível verificar a aplicabilidade dos conhecimentos arrolados. 
Alguns apontamentos dos acadêmicos, revelam para algumas dificuldades, como por exemplo de realização de atividades grupais, isto é atribuído, em virtude da gestão do tempo e, de algumas demandas de informações, que por sua vez, são necessárias para o desenvolvimento das atividades propostas.

Um grande destaque, está na qualidade dos trabalhos produzidos pelos estudantes, onde demonstram a capacidade adquirida de relacionar a teoria e prática.

\section{Considerações Finais}

A Educação a Distância cresce em grande velocidade no Brasil, mesmo ainda, apresentando barreiras, e por vezes, resistências em sua expansão, é inegável as possibilidades de acesso ao Ensino Superior que esta modalidade de ensino permite. Uma das resistências encontradas, diz respeito a falta de confiabilidade para uma aprendizagem ativa e, que tenha acepção, de fato, para os acadêmicos. Entretanto, a pesquisa evidenciou, por meio do uso do Projeto Integrador, que quando associa-se a uma boa arquitetura pedagógica, múltiplas linguagens e ainda eficientes recursos tecnológicos, a elaboração de conhecimentos experimental e ativa torna-se, totalmente, possível. Estas evidências, ficam claras na qualidade das produções realizadas pelos estudantes, apresentado capacidade teórica e prática, atitude para as resoluções dos problemas destacados e ainda, articulação interdisciplinar.

Referências

BERBEL, N. A. N. (2011). As metodologias ativas e a promoção da autonomia de estudantes. Semina: Ciências Sociais e Humanas

BRASIL. Lei de Diretrizes e Bases da Educação Nacional. Lei número 9394, 20 de dezembro de 1996.

DELORS, J. (Coord.). Os Quatro Pilares da Educação. In: Educação: um tesouro a descobrir. São Paulo: Cortezo. 1998.

MORAN, J. Convergências Midiáticas, Educação e Cidadania: aproximações jovens. Vol. II Carlos Alberto de Souza e Ofélia Elisa Torres Morales (orgs.). Coleção Mídias Contemporâneas. PG: Foca Foto-PROEX/UEPG, 2015. 
MORIN, E. Os Sete Saberes da Educação do Futuro. São Paulo: Cortez. 2002.

PIAGET, J. A Epistemologia Genética. Petrópolis: Vozes, 1971.

Vygotski, L.S. A Formação Social da Mente. São Paulo: Martins Fontes. 1998 